\title{
Impact of Aquatic Salinity on Mangrove Seedlings: A Case Study on Heritiera fomes (Common Name: Sundari)
}

\author{
Nabonita Pal ${ }^{1}$, Sufia Zaman ${ }^{1}$, Prosenjit Pramanick ${ }^{1}$ and Abhijit Mitra ${ }^{2 *}$ \\ ${ }^{1}$ Department of Oceanography, Techno India University West Bengal, India \\ ${ }^{2}$ Department of Marine Science, University of Calcutta, India
}

Received: August 20, 2017; Published: September 12, 2017

*Corresponding author: Abhijit Mitra, Department of Oceanography, Techno India University West Bengal, Salt Lake Campus, Kolkata 700091, India, Tel: 9831269550; Email: abhijit_mitra@hotmail.com

\begin{abstract}
Heritiera fomes (commonly known as Sundari in India) is gradually getting extinct from high saline pockets of lower Gangetic plain. Hydroponically grown seedlings of the species were analyzed for $\mathrm{Chl} \mathrm{a}, \mathrm{Chl} \mathrm{b}$, total chlorophyll, $\mathrm{Chl} a: b$ ratio and carotenoid at five different salinity levels $(2,5,10,15$ and $20 \mathrm{psu})$. The concentrations of chlorophyll and carotenoid pigments exhibited significant negative correlations with salinity ( $p<0.01)$. The total chlorophyll expressed, on unit fresh wt. basis decreased by $63.39 \%$ to $73.33 \%$ and in case of carotenoid the decrease was from $27.78 \%$ to $36.84 \%$ with the increase of salinity from 2 to 20 psu. The Chl $a: b$ ratio in the plant remained almost constant throughout the period of investigation during 2017 January. The results show that Heritiera fomes of Indian Sundarbans region can be sustained and propagated under low saline environment. At $15 \mathrm{psu}$, the plants become acclimated in one to two weeks, but at 20 psu the seedlings could not survive. The study is important as rising salinity is experienced in central Indian Sundarbans of lower Gangetic plain due to sea level rise and obstruction of freshwater flow from Ganga-Bhagirathi-Hooghly channel as a result of heavy siltation.
\end{abstract}

\section{Introduction}

Mangroves are the characteristic littoral plant formation of tropical and subtropical sheltered coastlines [1]. Being on the land sea interface, they are always associated with and subjected to saline seawater. However saline condition is not a prerequisite for their development, rather mangroves choose saline condition to avoid the competition with the more vigorous terrestrial plants. Based on the physiological studies, Bowman [2] and Davis [3] concluded that mangroves are not salt lovers, rather salt tolerants. But excessive saline conditions retard seed germination, impede growth and development of mangroves. Indian Sundarbans, the famous mangrove chunk of the tropics is gradually losing Heritiera fomes (commonly known as Sundari) owing to increase of salinity in the central sector of the delta complex around the Matla River. Reports of alteration of growth in mangroves due to difference in salinity between western and central sectors of Indian Sundarbans are available [4]. However no study has yet been carried on the effect of salinity fluctuation on the photosynthetic pigments and carotenoid level of mangroves under culture conditions from this part of the Indian sub-continent. The effects of salinity on mangroves have been studied in relation to antioxidative enzymes [5,6], leaf structure, rates of transpiration, stomatal conductance and rates of photosynthesis $[7,8]$ and changes in chloroplast structure and function $[5,9]$. Reported that $\mathrm{Na}^{+} / \mathrm{H}^{+}$antiport catalyzed exchange of $\mathrm{Na}^{+}$for $\mathrm{H}^{+}$across the vacuolar membrane of the cells of Bruguiera sexangula offered tolerance to ionic stress imposed by $\mathrm{NaCl}$ and this mechanism was important for cellular salinity adjustments. Also, the mechanism of acclimation to salt in mangroves was suggested to be linked to the changes in the vacuolar size in B. sexangula [10]. Further, one of the biochemical mechanisms by which mangroves counter the high osmolarity of salt was accumulation of compatible solutes [5].

In this paper, we present the effect of salinity on pigments in Heritiera fomes under hydroponic culture with an aim to obtain insights into the changes in chlorophyll and carotenoid level with salt acclimation. Such study is important from the point of sea level rise and subsequent saline water intrusion into the islands of Indian Sundarbans as the lower Gangetic delta complex is extremely vulnerable to climate change related effects owing to its location below the mean sea level and experiencing a sea level rise of $3.14 \mathrm{~mm} / \mathrm{yr}$. Moreover unlike other mangrove species Heritiera fomes prefer extremely low saline condition and hence can act as biological signal of climate change related to sea level rise. 


\section{Material and Methods}

\section{Plant materials and culture conditions}

Seeds of Heritiera fomes were collected from Sundarbans mangrove system of India (Figure 1). Seedlings were raised in the laboratory condition by diluting the water collected from high saline zones of Sundarbans (salinity $=30 \mathrm{psu}$ ) under photosynthetically active radiation (PAR) of 1220-1236 $\mu \mathrm{mol} \mathrm{m}{ }^{-2}$ $\mathrm{s}^{-1}$ during January 2017. Two-month-old healthy seedlings were selected for hydroponic culture in Hoagland's nutrient medium $(\mathrm{pH}$
= 5.8-6.0). The preliminary experiments were carried out in the selected species at five different salinities $(2,5,10,15$ and $20 \mathrm{psu})$ in order to determine the optimum range of salinities in context to photosynthetic pigments and carotenoids. The cultures were aerated continuously with an air bubbler. The hydroponic cultures were maintained in a culture room under a $14 \mathrm{~h}$ photoperiod at PAR of $300 \mu \mathrm{mol} \mathrm{m} \mathrm{m}^{-2}, 26 \pm 30 \mathrm{C}$, and $80 \% \mathrm{RH}$. The culture medium was changed every $7 \mathrm{~d}$. Leaves were harvested at 7, 14, 21 and $30 \mathrm{~d}$ intervals to measure the pigment concentrations.

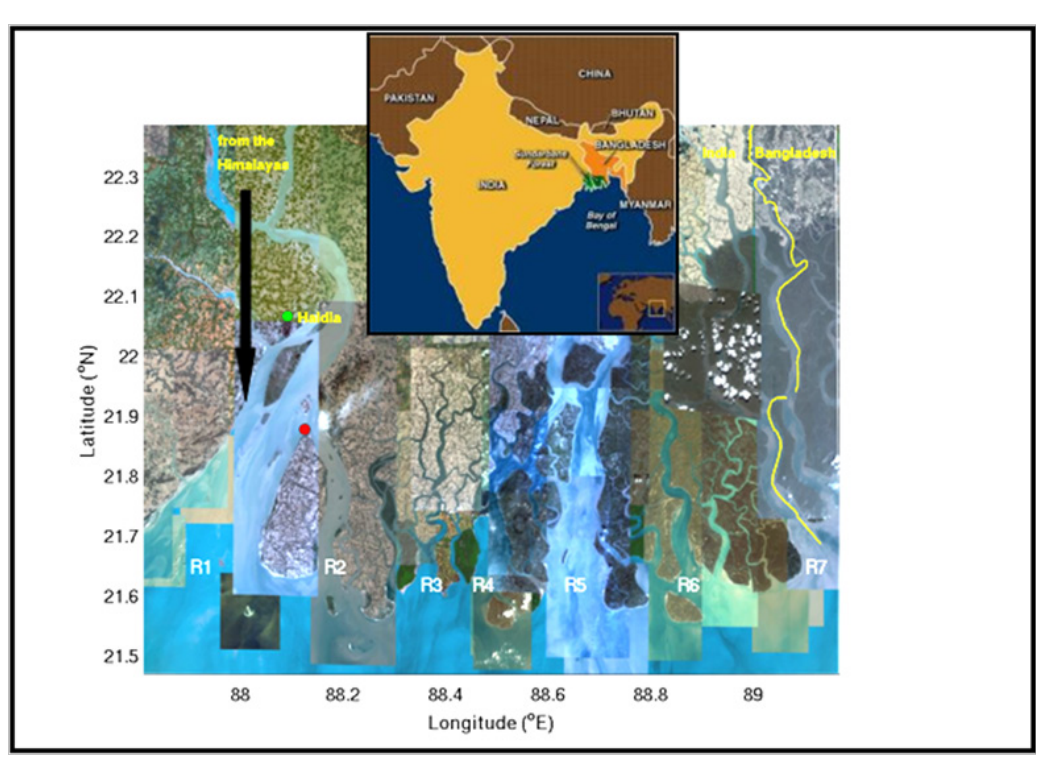

Figure 1: Map of the study region with 2 stations marked in red. The western station is located at $21^{\circ} 52^{\prime} 20.78^{\prime \prime} \mathrm{N}, 88^{\circ} 7^{\prime} 29.73^{\prime \prime}$ E, at the tip of Sagar Island. The seven rivers marked by R1 through R7 from west to east are: Hooghly, Muriganga, Saptamukhi, Thakuran, Matla, Gosaba and Harinbhanga. The discharge system of the two metropolises of Haldia and Kolkata (Calcutta) are connected to the two western rivers, which are also fed by the meltwater from the Himalayas after being regulated through barrages. The central station, at $22^{\circ} 15^{\prime} 33.97^{\prime \prime} \mathrm{N}, 88^{\circ} 39^{\prime} 34.64^{\prime \prime} \mathrm{E}$, is connected to the rivers R4 and R5 which do not have any freshwater input.

\section{Extraction and estimation of pigments}

Leaves $(0.5 \mathrm{~g})$ were homogenized in chilled $\mathrm{N}$, $\mathrm{N}$-dimethylformamide (DMF) in a mortar and pestle in the dark at $4^{\circ} \mathrm{C}$ and the homogenates were centrifuged at $8800 \times \mathrm{g}$ for 10 min. The supernatants were collected and absorption spectra at 663.8 and $646.8 \mathrm{~nm}$ were recorded using Jasco V-530 UV-vis spectrophotometer for estimation of $\mathrm{Chl} a$, Chl $b$ and total Chl following the procedure of Porra et al. [11]. For the estimation of total carotenoids, leaf tissues $(0.5 \mathrm{~g})$ were homogenized in chilled $80 \%(\mathrm{v} / \mathrm{v})$ acetone; the homogenates were centrifuged at 8800 $\times \mathrm{g}$ for $10 \mathrm{~min}$ at $4^{\circ} \mathrm{C}$ in the dark. The absorbance of the acetone extracts was measured at 663,645 and $470 \mathrm{~nm}$. Total carotenoids were calculated according to Arnon [12].

\section{Statistical analysis}

Statistical analysis of the results was carried out according to Duncan's multiple range tests. Data were also subjected to analysis of correlation coefficient (r) in order to evaluate the interrelationship between salinity and selected pigments [13].

\section{Results and Discussion}

We observed that the collected seedlings of Heritiera fomes could tolerate maximum salinity up to 15 psu and could be maintained for more than $30 \mathrm{~d}$. On increasing the salinity to 20 psu the leaves began to fall off after the second week, and thus all the experiments were done up to $30 \mathrm{~d}$ in the salinity level 2, 5, 10 and 15 psu treated plants. The unhealthy conditions of the experimental seedlings of Heritiera fomes at 20 psu may be attributed to their ambient salinity in the western sector of deltaic Sundarbans region from where they were collected which usually ranges between 2 psu to 10 psu [14]. Such low salinity in the western part of the study area is due to freshwater discharge from the Ganga-Bhagirathi-Hooghly River that has its origin in the Gangotri Glacier of the Himalayas.

The concentrations of chlorophyll and carotenoid pigments decreased significantly with the increase in salinity (Table 1 , Figures 2 \& 3). The total chlorophyll decreased by $38.54 \%, 44.00 \%$, $63.85 \%$ and $63.89 \%$ at $7,14,21$ and $30 \mathrm{~d}$ intervals respectively due to change of salinity from 2 psu to 15 psu. The Chl $a: b$ ratio in 
the plant, however, remained almost constant for the species and varied only marginally during the period under observation. In our experiments with differential salinity exposure the Chl $a: b$ ratio yielded a value between 3.00 to 3.41 (Table 1 ). It appears from the results that high salinity did not affect $\mathrm{Chl} a: b$ ratio even though the total chlorophyll content decreased at high salt concentration. A similar trend in carotenoid content, expressed in fresh wt. basis, was observed (Table 1). The pigment decreased by $26.32 \%$ at the end of $7 \mathrm{~d}, 19.04 \%$ at the end of $14 \mathrm{~d}, 33.33 \%$ at the end of $21 \mathrm{~d}$ and $27.78 \%$ at the end of $30 \mathrm{~d}$. The decrease of the selected pigments with aquatic salinity is statistically significant (Table 2). The decrease in chlorophyll content at higher salinity might possibly be due to changes in the lipid protein ratio of pigment-protein complexes or increased chlorophyllase activity [15]. Our results agree with several reports of decrease content of chlorophyll and carotenoids by salinity as reported in a number of glycophytes $[16,17]$. As the Chl $a: b$ ratio remained unaffected at high saline condition in the selected species, it appears that the light harvesting complex (LHCs) of thylakoid membranes are little altered by salt exposure. Units of all pigments are mg.gm ${ }^{-1}$ fresh weight; Different letters besides figures indicate statistically different means as at $\mathrm{p}$ $\leq 0.01$.

Table 1: Effects of different salinity on pigment concentrations in Heritiera fomes.

\begin{tabular}{|c|c|c|c|c|c|c|}
\hline Duration of treatment (d) & Salinity (psu) & Chl $a$ & Chl $b$ & Total Chl & Chl $a: b$ & Carotenoid \\
\hline \multirow{5}{*}{7} & 2 & $0.71 \mathrm{a}$ & $0.22 \mathrm{a}$ & $0.93 a$ & $3.23 \mathrm{a}$ & $0.19 a$ \\
\hline & 5 & $0.63 b$ & $0.19 \mathrm{~b}$ & $0.82 \mathrm{~b}$ & $3.32 \mathrm{~b}$ & $0.17 \mathrm{~b}$ \\
\hline & 10 & $0.50 \mathrm{c}$ & $0.15 c$ & $0.65 c$ & $3.33 \mathrm{~b}$ & $0.17 \mathrm{~b}$ \\
\hline & 15 & $0.43 \mathrm{~d}$ & $0.13 \mathrm{~d}$ & $0.56 \mathrm{~d}$ & $3.31 \mathrm{~b}$ & $0.14 \mathrm{c}$ \\
\hline & 20 & $0.26 \mathrm{e}$ & $0.08 \mathrm{e}$ & $0.34 \mathrm{e}$ & $3.25 \mathrm{a}$ & $0.12 \mathrm{~d}$ \\
\hline \multirow{5}{*}{14} & 2 & $0.58 \mathrm{a}$ & $0.17 \mathrm{a}$ & $0.75 a$ & $3.41 \mathrm{a}$ & $0.21 \mathrm{a}$ \\
\hline & 5 & $0.49 \mathrm{~b}$ & $0.15 b$ & $0.64 b$ & $3.27 \mathrm{~b}$ & $0.19 \mathrm{~b}$ \\
\hline & 10 & $0.41 c$ & $0.13 c$ & $0.54 \mathrm{c}$ & $3.15 c$ & $0.18 c$ \\
\hline & 15 & $0.32 \mathrm{~d}$ & $0.10 \mathrm{~d}$ & $0.42 \mathrm{~d}$ & $3.20 \mathrm{~b}$ & $0.17 \mathrm{~d}$ \\
\hline & 20 & $0.15 \mathrm{e}$ & $0.05 \mathrm{e}$ & $0.20 \mathrm{e}$ & $3.00 \mathrm{a}$ & $0.14 \mathrm{e}$ \\
\hline \multirow{5}{*}{21} & 2 & $0.64 a$ & $0.19 a$ & $0.83 a$ & $3.37 \mathrm{a}$ & $0.18 \mathrm{a}$ \\
\hline & 5 & $0.53 b$ & $0.16 \mathrm{~b}$ & $0.69 \mathrm{~b}$ & $3.31 \mathrm{~b}$ & $0.16 \mathrm{~b}$ \\
\hline & 10 & $0.47 \mathrm{c}$ & $0.14 \mathrm{c}$ & $0.61 c$ & $3.36 \mathrm{a}$ & $0.14 \mathrm{c}$ \\
\hline & 15 & $0.23 \mathrm{~d}$ & $0.07 \mathrm{~d}$ & $0.30 \mathrm{~d}$ & $3.29 \mathrm{~b}$ & $0.12 \mathrm{~d}$ \\
\hline & 20 & - & - & - & - & - \\
\hline \multirow{5}{*}{30} & 2 & $0.55 a$ & $0.17 \mathrm{a}$ & $0.72 \mathrm{a}$ & $3.24 \mathrm{a}$ & $0.18 \mathrm{a}$ \\
\hline & 5 & $0.51 b$ & $0.15 b$ & $0.66 \mathrm{~b}$ & $3.40 \mathrm{~b}$ & $0.15 b$ \\
\hline & 10 & $0.45 c$ & $0.15 b$ & $0.60 \mathrm{c}$ & $3.00 \mathrm{c}$ & $0.15 b$ \\
\hline & 15 & $0.20 \mathrm{~d}$ & $0.06 \mathrm{c}$ & $0.26 \mathrm{~d}$ & $3.33 \mathrm{~b}$ & $0.13 c$ \\
\hline & 20 & - & - & - & - & - \\
\hline
\end{tabular}

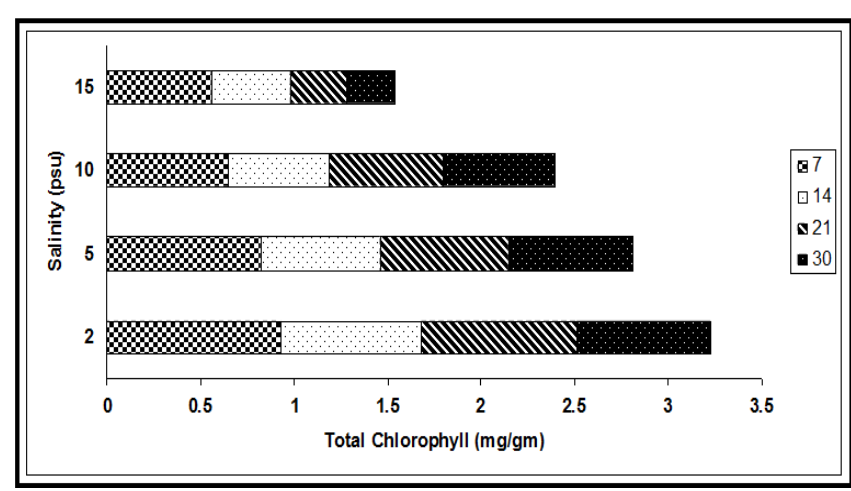

Figure 2: Variation of total chlorophyll content (mg/gm) at different salinities during different exposure days $(7,14$, $21 \& 30)$.

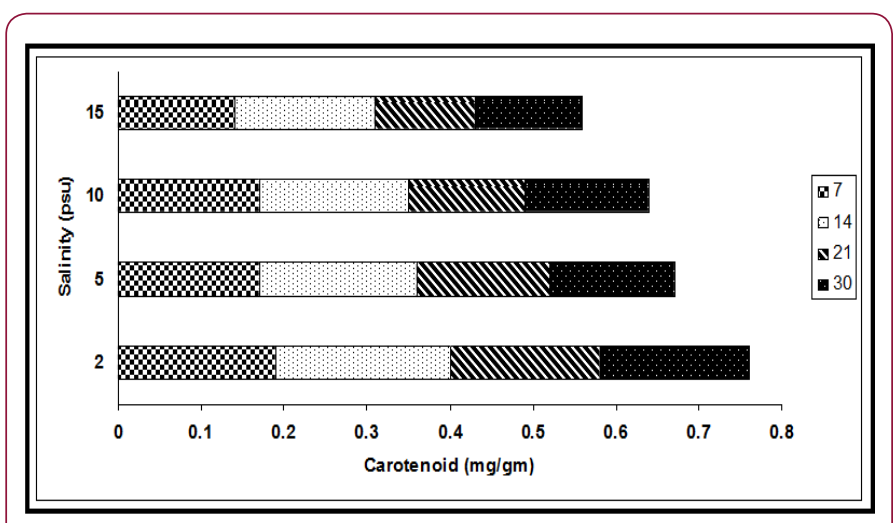

Figure 3: Variation in carotenoid content $(\mathrm{mg} / \mathrm{gm})$ at different salinities during different exposure days $(7,14$, 21 and 30). 
Table 2: Inter-relationships between salinity and selected pigments in Heritiera fomes (all cases $\mathrm{p}<0.01$ ).

\begin{tabular}{|c|c|}
\hline Combination & 'r' value \\
\hline Salinity $\times \mathrm{Chl} a$ & -0.9111 \\
\hline Salinity $\times \mathrm{Chl} b$ & -0.9018 \\
\hline Salinity $\times$ Total Chl & -0.9096 \\
\hline Salinity $\times$ Carotenoid & -0.7775 \\
\hline
\end{tabular}

The adverse impact of salinity on leaf chlorophyll of Heritiera fomes may significantly affect the rate of photosynthesis as this pigment is an indispensable raw material for running the process. Till date there have been few studies on the effect of salinity on photosynthetic gas exchange in mangroves. Clough [18] stated in his communication that the rate of light saturated photosynthesis decreases with increasing salinity of ambient media, attributing this to co-limitation of assimilation rate by stomatal conductance and photosynthetic capacity in response to differences in water status induced by the various salinity treatments. Thus, on the evidences available so far it is most likely that salinity exerts its effect on photosynthesis mainly through changes in leaf water status. The present study reveals that the photosynthetic process may be affected at high saline condition due to decrease in Chl $a$ and $b$ concentrations in Heritiera fomes. This present study is different from several previous works as the salinity of water has been altered naturally (through rain water dilution) keeping all the constituent salts of brackish water constant unlike several previous studies where the plants were exposed to different $\mathrm{NaCl}$ concentrations $[19,20]$ that are not the real image of ambient seawater. Various studies have shown that a number of mangrove species grow best at salinities between 4 psu and 15 psu [18,21-24] and for Heritiera fomes, the preferred salinity range is much lower [25]. Our results show that Heritiera fomes of Indian Sundarbans region can flourish luxuriantly under low salinity conditions. At 15 psu, the plants become acclimated to salt after one to two weeks of exposure, but at 20 psu the seedlings could hardly adapt.

Indian Sundarbans and its adjacent estuaries at the apex of the Bay of Bengal are one of the less studied regions of the world ocean in context to impact of rising salinity fluctuation on mangrove floral community, although the region sustains the $5^{\text {th }}$ largest mangrove chunk in the world $\left(2120 \mathrm{~km}^{2}\right.$ in the Indian part and $4500 \mathrm{~km}^{2}$ in the Bangladesh part). The present study is extremely important from the point of view of rising salinity in the central sector of Indian Sundarbans over a period of 2 decades [26] due to complete obstruction of the freshwater supply of Ganga-Bhagirathi-Hooghly River as a result of heavy siltation since the late $15^{\text {th }}$ century [25] and rising sea level [27] at the rate of $3.14 \mathrm{~mm} / \mathrm{yr}$, which is higher than the global average sea level rise of $2.12 \mathrm{~mm} / \mathrm{yr}$ and $2.50 \mathrm{~mm} /$ yr along the Indian coastline [28]. The pigments, being the key machinery in regulating the growth and survival of the mangroves require an optimum salinity range between 4 to 15 psu [22,23] for proper functioning.

Heritiera fomes, the freshwater loving mangrove species prefers an optimum salinity between 2 to 5 psu [29]. It appears from our results that the growth of the species would be better if freshwater of the western sector of Indian Sundarbans is channelized to the central sector through capital dredging (initially) and periodic dredging (yearly). The processes will not only help to ecorestore the system through recruitment of freshwater loving mangrove species (like Heritiera fomes, Nypa fruticans, Bruguiera gymnorhiza etc.), but may also help to combat the intrusion of seawater from the southern part of Sundarbans mangrove ecosystem due to expansion of the Bay of Bengal water on account of warming [29,30].

\section{References}

1. FAO (1994) Mangrove forest management guidelines. FAO Forestry paper, Rome 117.

2. Bowman (1917) Mangrove regeneration and management. In: A.K.F. Hoque, 1995. Mimeograph.

3. Davis JH (1940) The Ecology and Geological Role of Mangroves in Florida. Pap. Tortugas Lab 32: 303-412.

4. Mitra A, Banerjee K, Bhattacharyya DP (2004) The other face of mangroves. Department of Environment, Govt of West Bengal, India.

5. Takemura T, Hanagata N, Sugihara K, Baba S, Karube I, et al. (2000) Physiological and biochemical responses to salt stress in the mangrove, Bruguiera gymnorrhiza. Aquatic Botany 68: 15-28.

6. Parida AK, Das AB, Mohanty $\mathrm{P}$ (2004) Defense potentials to $\mathrm{NaCl}$ in a mangrove, Bruguiera parviflora: differential changes of isoforms of some antioxidative enzymes. Journal of Plant Physiology 161(5): 531542.

7. Santiago LS, Lau TSP, Melcher J, Steele OC, Goldstein G (2000) Morphological and physiological responses of Hawaiian Hibiscus tiliaceus population to light and salinity. International Journal of Plant Science 161(1): 99-106.

8. Parida AK, Das AB, Mittra B (2004) Effects of salt on growth, ion accumulation, photosynthesis and leaf anatomy of the mangrove Bruguiera parviflora. Trees-Structure and Function 18(2): 167-174.

9. Parida AK, Das AB, Mittra B (2003) Effects of NaCl stress on the structure, pigment complex composition and photosynthetic activity of mangrove Bruguiera parviflora chloroplasts. Photosynthetica 41: 191-200.

10. Hotta M, Nemoto S, Mimura T (2000) Re-evaluation of role of vacuole during salt adaptation in higher plant cells. Plant Cell Physiology 41: 79.

11. Porra RJ, Thompson WA, Kriendemann PE (1989) Determination of accurate extinction coefficients and simultaneous equations for assaying chlorophyll a and $\mathrm{b}$ extracted with four different solvents: verification of the concentration of chlorophyll standards by atomic absorption spectroscopy. Biochimca Biophysics Acta 975: 384-394.

12. Arnon DI (1949) Copper enzymes in isolated chloroplasts, polyphenol oxidase in Beta vulgaris. Plant Physiology 24(1): 1-15.

13. Sokal RR, Rohlf FJ (1995) Biometry: The Principles and Practice of Statistics in Biological Research. USA Pp. 887.

14. Mitra A (2000) The north-west coast of the Bay of Bengal and deltaic Sundarbans. In: Charles Sheppard (ed.) Seas at the Millennium: An Environmental Evaluation UK 2: 160.

15. Iyengar ERR, Reddy MP (1996) Photosynthesis in high salt-tolerant plants. In: M Pesserkali (ed) Hand Book of Photosynthesis. USA pp. 56-65.

16. Gadallah MAA (1999) Effects of proline and glycinebetaine on Vicia faba in response to salt stress. Biological Plant 42(2): 249-257.

17. Agastian P, Kingsley SJ, Vivekanandan M (2000) Effect of salinity on photosynthesis and biochemical characteristics in mulberry genotypes. Photosynthetica 38(2): 287-290. 
18. Clough BF (1985) Effect of nutrient supply on photosynthesis in mangroves. In: LJ Bhosale (Ed.), The Mangroves Proc Natl Symp Biol Util Cons Mangroves. Shivaji University, Kohlapur, India pp. 80-88.

19. Mishra S, Das AB (2003) Effect of $\mathrm{NaCl}$ on leaf salt secretion and antioxidative enzyme level in roots of a mangrove, Aegiceras corniculatum. Indian Journal of Experimental Biology 41(2): 160-166.

20. Netondo GW, Onyango JC, Beck E (2004) Sorghum and salinity: I. Response of growth, water relations, and ion accumulation to $\mathrm{NaCl}$ salinity. Crop Science 44: 797-805.

21. Connor DJ (1969) Growth of grey mangrove (Avicennia marina) in nutrient culture. Biotropica 1: 36-40.

22. Downton WJS (1982) Growth and osmotic relations of the mangrove Avicennia marina, as influenced by salinity. Australian Journal of Plant Physiology 9: 519-528.

23. Burchett MD, Field CD, Pulkownik A (1984) Salinity, growth and root respiration in the grey mangrove Avicennia marina. Physiologia Plantarum 60: 113-118.

24. Clough BF (1984) Growth and salt balance of the mangroves Avicennia marina (Forsk) Vierh, and Rhizophora slylosa Griff. in relation to salinity. Australian Journal of Plant Physiology 11: 419-430.
25. Chaudhuri AB, Choudhury A (1994) Mangroves of the Sundarbans, India. IUCN pp. 1: 284.

26. Mitra A, Gangopadhyay A, Dube A, Schmidt CK, Banerjee K (2009) Observed changes in water mass properties in the Indian Sundarbans (Northwestern Bay of Bengal) during 1980-2007. Current Science 97 (10): $1445-1452$.

27. Hazra S, Ghosh T, Dasgupta R, Sen G (2002) Sea level and associated changes in Sundarbans. Science and Culture 68(9-12): 309-321.

28. Lal M, Aggarwal D (2000) Climate change and its impacts in India, Asia-Pacific Jr. Environment \& Development 7(1): 1-41.

29. Mitra A, Zaman S, Banerjee K, (2009) Effects of Climate Change on marine and estuarine ecosystems with special reference to Gangetic delta. Journal of Indian Ocean Studies 16(3): 194-201.

30. Tanaka Y, Fukuda A, Nakamura A, Yamada A, Saito T (2000) Molecular cloning and characterization of mangrove $\mathrm{Na}^{+} / \mathrm{H}^{+}$antiporter cDNA. Plant Cell Physiology 41: 27.

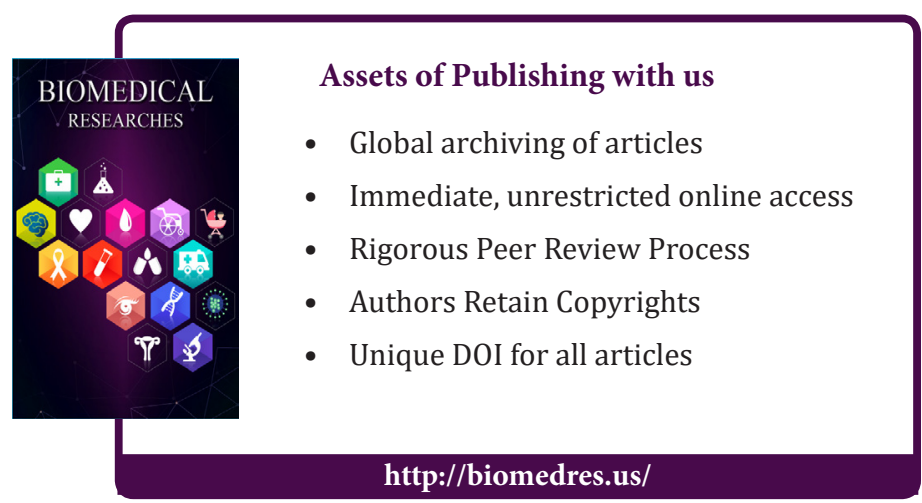

